\title{
Policy Framework for Transatlantic Peace Deal on Iran
}

\section{Peshawa Mohammed Ali}

Department of International Relations \& Diplomacy, Faculty of Administrative Sciences \& Economics, Tishk International University, Erbil, Kurdistan Region, Iraq.

E-mail: peshawa.ali@tiu.edu.iq

\section{Abstract:}

This research aims to explore the policy framework for the transatlantic peace deal with Iran focused on 2014-2020 era. As there have been calls and initiatives among leading European powers and the US in securing a transatlantic strategy for Iran. In a stable Multilateral NonProliferation Pact, The Joint Comprehensive Plan of Action (JCPOA) led by the European Union (EU) has reported immense success within its first few weeks of adoption (Paolo Magri, Annalisa Perteghella, 2017). It was also hoped that the EU and the United States (US) would open the door to deal with other pending problems with Iran (Adebahr, 2017). Europe and Iran: The nuclear deal and beyond. Routledge.. The Atlantic Ocean Council (ACOE), the European Leadership Network, and the European External Relations Council had planned another scheme abroad in recent months. This scheme takes into account warnings about the unraveling of the JCPOA and various sources of regional instability and government aid to traditional Middle Eastern citizen communities. This study focuses on the advancement of proposals for JCPOA security, regional peace, and improvement for the E3 and the European Union, and individuals who work with the strengthened US Organization to establish contacts with Iran. The research assesses the preparations for lifting of transatlantic sanctions against Iran, as well as the agreements reached between Iran and other signatories. This study follows descriptive analysis depending on data, which is gathered, from a number of scientific publications, published documents, magazines, and reputable websites. Thus, this paper seeks to investigate on the US-Iran peace impacts on the political stability in the region and the main challenges that the peace deal encounter.

Keywords: Policy Framework, Peace Deal, United States, Iran, European Union. 


\section{INTRODUCTION:}

World crises have worsened, including Iran's increasing nuclear program, until the US presidential election in 2020, November. Tehran did not only retreat from its obligations under the nuclear agreement with the Trump administration's complete pressure program, but it also contributed to intense transatlantic divisions (Scazzieri, 2021). Iran's policy needs modern activism that unites America with its most proximal conventional European allies with a new US Government on the horizon. The United States, France, Germany, and the United Kingdom debated a standard solution to Iran. Since the Trump administration decided to withdraw from the agreement in May 2018, the administration previously stated that it was ready to reintroduce the Iran agreement of 2015, also known as the Joint Comprehensive Action Plan (JCPOA) (Burns et al., 2021).

Four years of the Government of Trump left JCPOA tattered and seriously weakened multilateralism and international law values and foundations (Bilal, K, 2019). The flagrant maneuver by his administration against the JCPOA has affected the credibility of the Security Council. Its conduct worried the Europeans insofar as, an informal declaration, France, Germany, and the United Kingdom felt obligated to stress that they remained engaged to preserve the mechanisms and structures that underlie multilateralism (Burns et al., 2021). Strategies globally have grown in the number one position leading up to the United States' official political voting in November, relying on Iran's growing atomic database. The Trump administration's most successful compression factor campaign has sparked serious transoceanic partitions as well as Tehran's withdrawal from its obligations under the nuclear agreement (Entessar, N., \& Afrasiabi, K. L, 2019). With another US organization not far behind, Iran's policy involves revolutionary participation that unites the US with its closest traditional allies in the European Union (Fisher and Simakovsky, 2020). As seen from Europe, the diplomatic fallout from the Trump administration applies to relations with China and Russia, the two parties to the JCPOA. Rather than taking concrete action to defend the JCPOA, both countries seemed to have generally followed Napoleon Bonaparte's philosophy of never interrupting an opponent who made a mistake. Their policy paid off, with Iran being thrust strategically and economically into the arms of Beijing and Moscow. By the fall of 2020, the US had essentially alienated itself to the point that Europe may be moved to side with Moscow and Beijing in rejecting Washington's Security Council moves against the JCPOS and supported come back to negotiation. (Geranmayeh, Slavin, and Shah, 2020)

According to Burns et al. (2021), none is more eligible for the task than the US partners in Europe, who recently played a great role in the transactions that led to the 2015 Joint Comprehensive Action Plan (JCPOA). Despite the unilateral removal by the United States of the same agreement in 2018 (Jalilvand and Adebahr, 2020), the disadvantage of draconian approvals by the Trump organization and increasing pressure in the Middle East, England, France, and Germany - E-3 - and the European Union have worked hard on keeping JCPOA alive. As the current US strategy threatens to weaken the bedrock of Europe's peace and development, and Iran leads to intensified uncertainty in its immediate neighborhood, the EU's response to Iran must be reconsidered (Dershowitz, 2015). Notably, in this case, where Biden won the electoral race, Europe will have to rapidly shift gears from battling for the JCPOA's survival to developing realistic plans, backed up by political will and finances, to forge a new transatlantic policy toward Iran (Julien Barnes-Dacey, 2020). The window of opportunity was limited: other government stakeholders in Europe were unable to negotiate substantively with the new Biden team during the transition phase, ranging from the election to the President's inauguration. Doing so would have constituted an international intervention. (Berger, Farzan. 2021). 


\section{Review of Literature}

This section deals with theoretical context, which includes various strategies that are in place to assess how the negotiations between multiple parties involved in the Iran nuclear deal. It analyses various meetings, including the one held in Vienna, the first one after the United States withdrew from the negotiations in 2018. The advancements that have been made since President was elected are also critically evaluated. Since there were no direct negotiations between the two countries, various intermediaries such as the EU, France, and the UK were involved in understanding the parties.

\subsection{The Iran Nuclear Deal}

As indicated by Dershowitz (2015) Iran nuclear agreement, officially known as the Joint Comprehensive Plan of Action (JCPOA), was signed in July 2015 by Iran and other world powers, such as the United States. In exchange for billions of dollars in sanctions, Iran agreed to abandon most of its nuclear program and allow its plants to more rigorous foreign surveillance (Chehabi, Jafari, and Jefroudi, 2018). Nevertheless, after President Donald J. Trump excluded the US from the deal in 2018, the arrangement has always been in doubt (Dershowitz, 2015). Iran has revived several nuclear programs in retribution for the US withdrawal and brutal attacks on influential Iranians in 2020, such as one in the United States ("Renewing transatlantic strategy on Iran - Atlantic Council," 2021). President Joe Biden has claimed that the US will commit to the arrangement if Iran returns to conformity, but analysts believe that revived diplomacy will face significant political obstacles (Geranmayeh et al., 2020; Dershowitz, 2015).

\subsection{Plan for the Revival of Transatlantic Policy on Iran}

In this context, Burns (2021) stresses the point that it is necessary to remember that keeping the JCPOA in place is not, and should not be, an end in itself. The nuclear deal is only one source of worry for world powers seeking regional stability; another is Iran's propensity for regional destabilization, whether by funding for proxies or its missile program. Europe shares the United States' concern about the regime's poor human rights record, including anti-Semitism and homophobia (Patrick, 2021). In contrast, with nuclear energy projects now operational in the United Arab Emirates and Saudi Arabia, the nuclear issue has taken on a strong regional dimension. Resuming negotiations on the JCPOA should also consider the geographical context ("Renewing transatlantic strategy on Iran - Atlantic Council," 2021).

Similarly, the nuclear agreement was intended to lead to regional and international stability and security favorably. According to Burns (2021), most governments in Europe were also banking on a steady shift within Iran. To that end, and following its fundamental foreign policy orientation, Europe aimed to engage Iran rather than isolate it (Jalilvand and Adebahr, 2020). The EU's comprehensive policy plan, including economic affairs, energy, the economy, migration, narcotics, humanitarian assistance, transportation, civil defense, scientific and civil nuclear cooperation, and culture, demonstrates this (Dershowitz, 2015). In this regard, Chehabi et al. (2018) argue that there needs to focus on a limited number of urgent and tangible initiatives with a high chance of success. Three projects should be prioritized: ending the COVID-19 pandemic, resume negotiations between Iran and the US, and merging US and Iranian technology policies. ( Berger, Farzan. 2021) 


\section{Step one: Resume Negotiations about Iran Nuclear Program}

President Biden recently sought to resume negotiations with Iran over the 2015 nuclear deal, which the former President, Donald Trump, reneged on three years after it was agreed upon (Scazzieri, 2021). According to Pattrick (2021), both countries will take coordinated measures to get Iran into line with the terms of the deal while eventually lifting sanctions. Iran has resisted, and China has backed it up, insisting that the US first act to resurrect the agreement it broke by repealing unilateral sanctions that have smothered the Iranian economy (Jalilvand and Adebahr, 2020).

\section{Step two: Forge a United front on Technology}

The transatlantic partnership should ensure the protection, protection, and usability of this infrastructure a top priority. The formation of a Transatlantic Trade and Technology Council is a reasonable way to begin (Scazzieri, 2021). The accurate measure of progress, though, would be if the US and Iran are willing to take drastic steps to build a united front on new technology (Fisher \& Simakovsky, 2020). The first sequence of activities should defend the US and Iranian communities from foreign governments who may exploit technologies for harmful purposes (Fisher and Simakovsky, 2020).

\section{The current state of the Negotiations}

By all possible means, the talks that have been held between the US and Iran seemed to be successful and of achieving a significant relationship between these warring countries (Patrick, 2021). Two proficient working clusters were formed to deal with sanctions and the nuclear-related issues to try and come up with a solution and advance a mechanism (Simpson, K. 2015). That would see the United States and Iran agree to the terms set earlier in a joint deal reoffered to as a Joint Comprehensive Plan of Action (JCPOA). The two parties also agreed to meet later and discuss advancements in this talk which is a definite indication of immense progress (Patrick, 2021). Comments made by both the United States and Iranian governments gave more understanding of what these parties discussed on the table ("Renewing transatlantic strategy on Iran - Atlantic Council," 2021).

The United States, in the press after meetings, acknowledged that they were prepared to lift the sanctions that are not following the agreements stipulated in the JCPOA and also clash with the paybacks that Iran expects to gain from the deal in the way of showing appreciation to the acceptance of Iran to participate in these talks (Scazzieri, 2021). The sanctions lifted refereed to those on nuclear placed by the then President, Donald Trump during his administration and had gone against the JCPOA commitments. The speech to the press also touched on non-nuclear-related sanctions that had been placed on Iran. For instance, sanctions on terrorism link to some of the full Iranian cooperation, such as the Central Bank and the National Iranian Tanker Company. Even though they were not unreliable with JCPOA, lifting them will make the Iranian government enjoy the benefits related to this deal, thus restoring the Transatlantic Policy agreements. For more than half its lifespan, the JCPOA has contended not just with the absence of a key participant, but with active U.S. efforts to undermine it. That the deal survives at all highlights the strength of its core bargain: rolling back Iran's nuclear activity for economic respite from sanctions emplaced in response to those very activities. Restoring that understanding is essential, and with the imminent arrival of a new U.S. administration under President-elect Joe Biden, also viable. But it will require both Washington and Tehran, along with the deal's other participants, to move quickly and in good faith toward 


\section{Journal of University of Raparin}

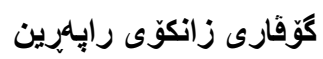

E-ISSN: 2522 - 7130 P-ISSN: 2410 - 1036

reviving the agreement. Subjecting diplomacy to leverage-focused one-upmanship and additional demands by either side would cause discord as predictable as it is avoidable. (Crisis group2021)

\subsection{Unpredictable Iran's Nuclear Track}

Apart from the talks on sanctions lifted and those placed on Iran by the United States, not much is known about the activities revolving around their nuclear track (Chehabi et al., 2018). According to Jalilvand and Adebahr (2020), reports indicate that this crucial issue was not addressed during the debate held between the two countries. Iran is known for how they constantly talk about its ability to reactivate its nuclear activities. In contrast, the United States maintains that such actions do not outdo the laws to govern atomic manufacture and usage in various countries worldwide (Barnes-Dacey, 2020). Thus, it would be of the essence if the United States asked the Iranian government to allow the relevant authorities to take charge and control their nuclear plants before proceeding to restore the relationship between them (Geranmayeh et al., 2020). Such would ensure that the debate is conducted on fairgrounds before Iran considers reducing their nuclear production activities.

Also, confirming that Iran's comeback to nuclear-related activities adheres to the regulations set by the JCPOA and that going against such measures would mean severe violations of the efforts that various countries have tirelessly put in to realize this deal comes into place (Sauer, 2007). Though not included in this deal, the United States would likely also evaluate the progress being made by Iran in the nuclear reclamation program for a year to ensure that they do not break out from the agreed terms since the JCPOA has put in place technical restraints that would affect the United States' political influence across the world and their aptitude to produce nuclear weapons (Burns et al. 2021). To achieve this, examples of undertakings that may require discussion include the plan by Iran to expand and use more advanced centrifuges in the production process of nuclear materials and their intent to engage in the extraction of Uranium metal. Therefore it's quite safe to conclude that the nuclear tension between the United States and Iran would have less tension if the sanctions were taken out of the picture, of which this is quite difficult to realize.

Meanwhile, both countries are yet to meet and deliberate on this issue, especially the United States side, making their objectives less known to the public (Fisher and Simakovsky, 2020). During the meeting between these two countries, The United States appeared to show some flexibility. At the same time, Iran was very keen on the aspects they pointed out during and after these negotiations. Issues that Iran appeared to have a firm stand included the removal of all sanctions that had been put in place by the former administration of Donald Trump, that before returning to the required nuclear guidelines, Iran would inspect and ascertain that these sanctions had been removed (Jalilvand and Adebahr, 2020). Finally, Iran had a view on how their demands were to be met. They wanted their requests all met at once and not in a step-by-step process. A more positive indication during the talks was that Iran was ready to engage at a table with the United States. With this in place, then the success of the efforts to achieve this policy in the area will depend mainly on the demands of Iran.

\subsection{Demands by Iran}

Concerning the first demand made by Iran, several Iranian officials have done everything possible to emphasize that when they say all sanctions levied under Trump should be lifted. They imply all sanctions, including those linked to Iran's missile program, cyber operations, and human rights issues, which would be allowable under the deal (Chrysochou, Dalaklis, 2011). The US has stated unequivocally that the entire slate would not be removed. As a result, the question becomes: how flexible is Iran's status, if at all? 
It's also challenging to see what the US can offer to meet Iran's second demand: lifting all restrictions, followed by a timeframe during which Iran verifies that they have been lifted and only begin to tone down its nuclear program. Attempting to replicate the JCPOA's implementation phase - under which the US first issued sanctions exemptions (Adoption Day), went into effect once Iran fulfilled its nuclear commitments (Implementation Day); does not appear to be a viable option. According to verifying, removing sanctions could include successfully exporting oil, writing new oil deals, and executing money transfers through various channels (Barnes-Dacey, 2020). It's one way to make a symbolic oil delivery, but quite another to request Iran sign several new deals. Eventually, Iran's request that everything occurs at once, which seems to conflict with its requirement that the US - is probably the most straightforward to overcome, assuming Iran can specify a detailed description and series of measures that each side can take underneath a "unique" step. According to the latest Iranian comments, Tehran might well be accessible to such an approach. This would be similar to the JCPOA's Implementation Plan, except without the periods of transition: it really would commence with countries taking the very first measures and end since they were done.

\section{Agreements between Iran and other Signatories}

\subsection{Iran's Agreements}

Restriction on nuclear weapons (Dershowitz, 2015), Iran agreed to stop producing weapons-grade uranium and plutonium, all of which could be used in nuclear weapons. It also took actions to ensure that its installations in Fordow, Natanz, and Arak are used only for civilian purposes, such as research and cosmetic research. The agreement reduces the number and varieties of centrifuges Iran could use and the amount of processing, and the scale of its plutonium stockpile. Uranium that has been enriched to a concentration of 5\% is used in nuclear power plants. In comparison, uranium improved to a concentration of $20 \%$ would be used in nuclear reactions or for medicinal reasons. Atomic bombs are composed of solid uranium, 90\% pure (Cheabi et al., 2018).

Surveillance and verification are essential. Iran agreed to gradually introduce an agreement allowing the International Atomic Energy Agency (IAEA), the UN's atomic regulator, unrestricted admission to its nuclear sites and possibly undisclosed locations. The checks are meant to prevent Iran from developing nuclear weapons in secret, as reportedly attempted in the past. The International Atomic Energy Agency (IAEA) has given financial statements to its governing body and the UN Security Council about Iranian nuclear obligations (Dershowitz, 2015). The checks are meant to prevent Iran from developing atomic weapons in secret, as reportedly attempted in the past. The International Atomic Energy Agency (IAEA) has given financial statements to its governing body and the UN Security Council about Iranian nuclear obligations. The JCPOA, which includes members from all of the bargaining sides, oversees the agreement's execution and addresses any conflicts that might occur. IAEA inspectors will obtain access to questionable, undisclosed sites with a majority vote of its members. The agency is also in charge of transferring atomic power and dual materials. 


\subsection{Other Signatories Agreement}

Relief from sanctions. The European Union, the United Nations, and the United States have all agreed to lift their nuclear-related sanctions against Iran. Even so, several other US sanctions against Iran remained in place, some stretching back to the 1979 missile crisis. They address issues like Iran's ballistic missile program, funding for terrorist organizations, and human rights violations. Despite its commitment to remove sanctions on oil exports, the US maintained financial transaction controls, which have stifled foreign trade towards Iran (Dershowitz, 2015). The blockade on arms. The parties decided to lift a previous UN embargo; if the IAEA validates that Iran is now only involved in peaceful nuclear operations for five years, Iran will move conventional bombs and missile systems.

\section{Research Methodology}

The methodology utilized in this research is content analysis; this study is considered as descriptive study, which requires information and analysis based on the existing literature. Secondary data analysis was used to select papers and comprehensive research is made on the topic for this analysis, and the findings were examined and the results were provided. The information presented in this study was collected from secondary sources of data including mainly journal articles and newspapers; for this purpose, a desk research technique is used to get required information for discussing the topic in detail.

\section{DISCUSSION}

Through re-examine the findings of previous studies, we realize that the E-3 has initiated an online mechanism at the level of the Joint Commission, preferably at the level of foreign ministers, to see if the arrangement is better restored. These discussions sought to define the terms of an interim agreement that Iran and a Biden regime should recognize soon after the new US administration assumes office. During the transformation period in the United States, the E3 should clarify what is needed for Iran to freeze nuclear operations that meet the limits of the JCPOA. This is expected to depend heavily on the Biden administration's sanctions relief package (Geranmayeh et al., 2020).

In particular, the context of these high-level talks is how, by Iran's efforts to undo its nuclear expansion, Iran synchronizes lifting sanctions. European countries are working with Iran to create trust. For example, European governments, which are INSTEX stakeholders, should urge their leadership to visit Tehran more often for importers hit by sanctions to be directly contacted. In this way, we will determine, how the humanitarian trade can be strengthened. The E3/EU, with the US in the field of artillery missiles, ballistic missiles, cruise missiles, strike airplanes, and armed drones, has launched a process for consultation with regional states on the role of multilateral measures in the conflict to build confidence, such as advanced warning on missile testing and potential constraints on type and range of ballistic missiles. Eleven countries have long-range rockets in the area (Burns et al., 2021). Without a broader debate on the international strategic balance of strength, Europe and the United States will undoubtedly make no progress with sole emphasis on Iran's capability for missiles. Indeed, it has stabilized a transatlantic divide that saw European people trailing. It is one of the only accomplishments of this 'maximum pressure' strategy. Repeated attempts to get everyone to the negotiation table have been unsuccessful. Instruments that could facilitate resumed economic exchanges with Iran without infringing on US sanctions such as INSTEX have, until now, been meaningless. JCPOA provided Tehran with an opportunity to trade freely with the world (Scazzieri, 2021), particularly the EU. In this way, the dysfunctional severe Iranian 
economy resuscitates as trade began to recover when it was signed. Still, it was soon evident that significant obstacles had to be overcome due to the domestic structures and resistance.

In practice, the US approach to "maximum pressure" has enforced the stance of Iran and the IRGC in particular. Renewed US sanctions have harmed the Iranian economy and, in some ways, strengthened internal divisions within Iran but are not enough, as some people initially wished, to provoke a regime change (Geranmayeh et al., 2020). The Iranian leaders were not specifically persuaded to reinforce their ballistic and regional operations or reach an agreement with the U.S. Iran remained in nuclear power. Thus, landmarks were approaching the deal, political pressure was increasing in the run-up to the presidential elections, and global pandemic undermining leaders on both sides.

However, Europe's governments, the United States, and other agreement participants are searching for ways to increase projects for civil nuclear cooperation with Iran. This matters particularly for maintaining a friendship with the Iranian atomic company and mitigating predictable questions about proliferation EU envoy has also discussed the provisions on nuclear deterrence, safety, and protection that could be adopted in conjunction with Iran and the Gulf Cooperation Council (GCC). That includes the ratification of the supplementary Protocol to the Treaty on Nuclear Weapons Non-Proliferation (NPT), international nuclear safety agreements, limitations on enriched uranium percentages and stocks, and prohibition of reprocessing plutonium (Burns et al., 2021).

\section{CONCLUSION}

The Iranian nuke capability has put transatlantic ties to the test once again. Transatlantic relations seemed to diverge dramatically during the early years of George W. Bush Jr.'s presidency and gone worse during Trump's administration. Transatlantic ties began to intensify after 2020. The EU persuaded the US to resume talks with Iran, and the US had started to support the EU-3's initiatives ("UNODA - United Nations Office for Disarmament Affairs," 2021). Moreover, during Obama's presidency, transatlantic cooperation proceeded, with both sides taking the same firm position towards Iran. The appointment of many pro-American European governments brought the two sides much closer together. Finally, it was challenging to differentiate the EU's strategy from that of the United States. The only difference between the EU and the US was that the US had the option of using military force against Iran, which the EU has also consistently rejected.

The EU's plan has changed for a variety of reasons. To conclude, transatlantic ties were seriously harmed as a result of the US-led invasion of Iraq; thus, the Iranian nuclear program presented an excellent opportunity for change. The EU too was concerned about the US's interventionist and military approach to Iran, so it sought to provide an alternative. The victory of Ahmadinejad and his hostile policy and rhetoric pressured the EU-3 to adopt a stricter stance to convince Iran to give up its nuclear ambitions.

During this point, we could highlight the EU policy's progress in gaining support from the United States, Russia, and Asia for its policies. During its direct negotiations with Iran, the EU maintained a remarkable level of consistency, focusing primarily on optimizing strategic advantages instead of thoroughly resolving Iranian issues. Throughout their involvement, the EU made significant efforts to persuade Iran to increase international interest in its nuclear project's comfortable world. The EU, in particular, played a crucial role in negotiating a deal. While atomic warheads can be used legally in a specific context and under particular conditions, they pose a constant danger to countries because a "misunderstanding" can lead to catastrophe (Santini, 2010). Throughout this context, the production and acceleration of nuclear programs, especially by historically anti-western ideology states, has alarmed both the US and Europe, resulting in a wide range of responsive policies and strategies between the two superpowers constituting a constant point of contention in their tie. 


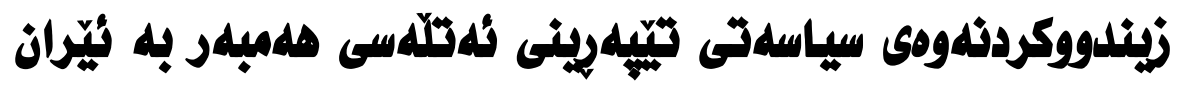

\section{بيّشلهوا محمل على}

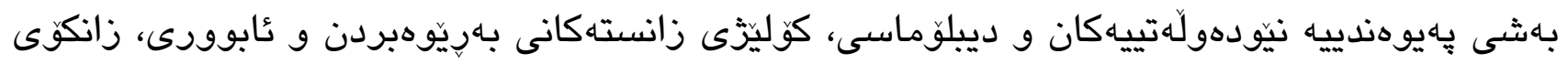

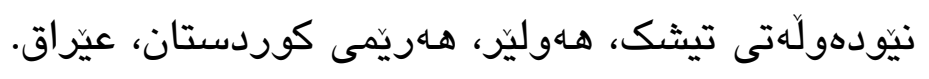
peshawa.ali@tiu.edu.iq :يميلم

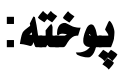

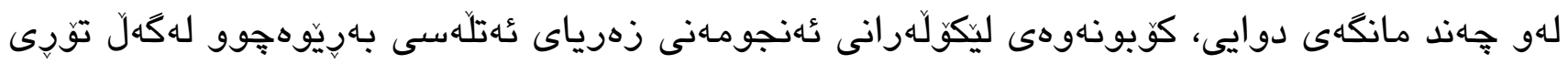

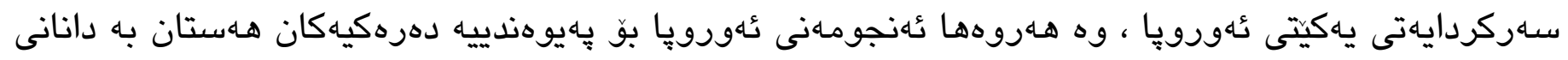

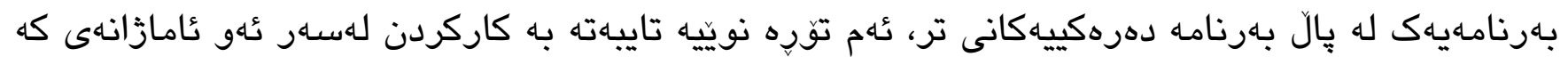

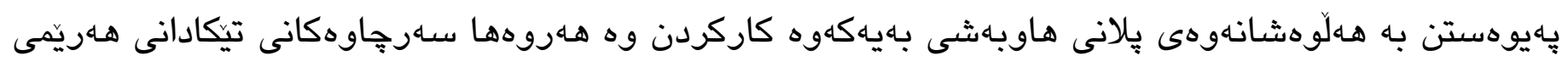

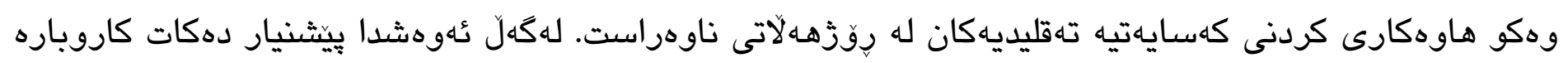

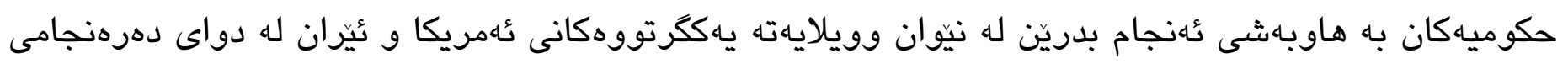

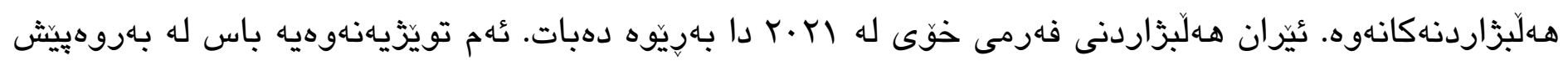

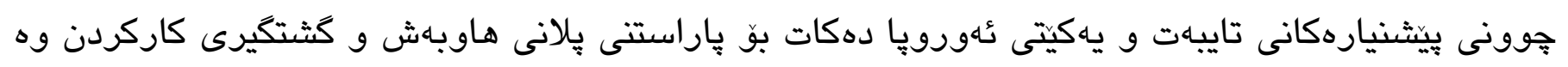

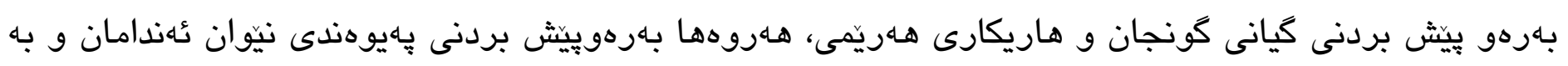

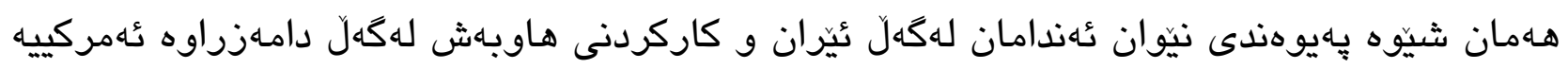
تايبهتمهندهان. كليله ووشلكان: رامياريهكان ، ئيزان ، وويلايهته يهككرتووهانى ئهمريكا، هاوكارى، ئابلّقةه 


\section{REFERENCES:}

Adebahr, C. (2017). Europe and Iran: The nuclear deal and beyond. Routledge.

Magri, P., \& Perteghella, A. (2017). Post-vote Iran: giving engagement a chance. Post-vote Iran, 1-147.

Belal, K. (2019). Uncertainty over the Joint Comprehensive Plan of Action: Iran, the European Union and the United States. Policy Perspectives, 16(1), 23-39.

Burns, N., Schwarzer, D., Taussig, T., Ashbrook, C., Nuland, A., Sanger, D., \& Sloat, D. (2021). Stronger Together: A Strategy to Revitalize Transatlantic Power. Retrieved 3 May 2021, from https://www.belfercenter.org/publication/stronger-together-strategy-revitalize-transatlantic-power.

Entessar, N., \& Afrasiabi, K. L. (2019). Trump and Iran: From containment to confrontation. Lexington Books.

Fisher, E., \& Simakovsky, M. (2020). A three-step plan for reviving the transatlantic alliance - Atlantic Council. Retrieved 3 May 2021, from https://www.atlanticcouncil.org/blogs/new-atlanticist/a-three-step-plan-forreviving-the-transatlantic-alliance/

Geranmayeh, E., Slavin, B., \& Shah, S. (2020). Renewing Transatlantic Strategy on Iran. Atlantic Council, 3-11. Retrieved from https://www.atlanticcouncil.org/wp-content/uploads/2020/11/Transatlantic-Strategy-IranIB.pdf.

Jalilvand, D., \& Adebahr, C. (2020). A Return to Diplomacy | DGAP. Retrieved 3 May 2021, from https://dgap.org/en/research/publications/return-diplomacy.

Renewing transatlantic strategy on Iran - Atlantic Council. (2021). Retrieved 4 May 2021, from https://www.atlanticcouncil.org/event/renewing-transatlantic-strategy-on-iran/

Julien Barnes-Dacey, T. (2020). A new transatlantic bargain: An action plan for transformation, not a restoration. Retrieved 3 May 2021, from https://ecfr.eu/publication/a-new-transatlantic-bargain-an-action-plan-fortransformation-not-restoration/ .

Patrick, S. (2021). What Are Biden's Actual Prospects for Reviving Trans-Atlantic Relations? Retrieved 3 May 2021, from https://www.worldpoliticsreview.com/articles/29342/what-are-biden-s-actual-prospects-forreviving-trans-atlantic-relations.

Scazzieri, L. (2021). A new transatlantic consensus on Iran. Retrieved 3 May 2021, from https://www.cer.eu/insights/new-transatlantic-consensus-iran.

Chehabi, H. (2015). "Iran in the Middle East: Transnational Encounters and Social

History", IB Tauris

Chehabi, H., Jafari, P., \& Jefroudi, M. (2018). Iran in the Middle East. London: IB Tauris.

Chrysochou, G. and Dalaklis, D. (2011). Demographic Transition and Civil Conflict in the Arab World, Strategy Paper Review Vol I, Strategy International, Thessaloniki. 
Chrysochou, G. (2015). European Security Strategy”, Common Security and Defense Policy Seminar, Piraeus. Hellenic Naval Academy-European Security and Defense College (ESDC).

Dershowitz, A. (2015). The Case Against the Iran Deal: How Can We Now Stop Iran from Getting Nukes. Rosetta Books.

United Nations Office for Disarmament Affairs, Nuclear-Weapon-Free Zones, 2016. Available at https://www.un.org/disarmament/wmd/nuclear/nwfz/.

UNSC, "Security Council Extends until July 2016 Panel of Experts to Support Committee Monitoring Iran Sanctions, Agreeing to Review Matter as Developments Warrant", 9 June 2015. Available at http://www.un.org/press/en/2015/sc11922.doc.htm.

Sauer, T. (2007). Coercive Diplomacy by the EU. The Iranian Nuclear Weapons crises. Third World Quarterly, 28(3), 613-633.

Santini, R.H. (2010). 'European Union Discourses and Practices on the Iranian Nuclear

Programmed'. European Security, 19, 3, 467-489

I. US nuclear diplomacy with Iran: From the war on terror to the Obama administration. Rowman \& Littlefield.

Berger, M., Farzan A. (2021). The United States is trying to salvage the Iran deal. Here's how both countries have broken with the pact. The Washington Post, https://www.washingtonpost.com/world/2021/04/06/irannuclear-deal-biden-sanctions-faq/ April 13, 2021

Crisis group, REPORT 220, (2021) The Iran Nuclear Deal at Five: A Revival? https://www.crisisgroup.org/middle-east-north-africa/gulf-and-arabian-peninsula/iran/220-iran-nucleardeal-five-revival, 15 JANUARY 2021 